\title{
Identification of liver CYP51 as a gene responsive to circulating cholesterol in a hamster model
}

\author{
Haiqiu Huang ${ }^{1}$, Zhuohong Xie ${ }^{2}$, Wallace Yokoyama ${ }^{3}$, Liangli $\mathrm{Yu}^{4} *$ and Thomas T. Y. Wang ${ }^{1} *$ \\ ${ }^{1}$ Diet, Genomics and Immunology Laboratory, USDA-ARS, Beltsville, MD 20705, USA \\ ${ }^{2}$ International Chemistry Testing, Milford, MA 01757, USA \\ ${ }^{3}$ Processed Foods Research, USDA-ARS, Albany, CA 94710, USA \\ ${ }^{4}$ Department of Nutrition and Food Science, University of Maryland, College Park, MD 20742, USA
}

(Received 24 November 2015 - Accepted 5 January 2016)

Journal of Nutritional Science (2016), vol. 5, e16, page 1 of 12

doi:10.1017/jns.2016.3

Abstract

Hypercholesterolaemia is a risk factor for CVD, which is a leading cause of death in industrialised societies. The biosynthetic pathways for cholesterol metabolism are well understood; however, the regulation of circulating cholesterol by diet is still not fully elucidated. The present study aimed to gain more comprehensive understanding of the relationship between circulating cholesterol levels and molecular effects in target tissues using the hamster model. Male golden Syrian hamsters were fed with chow or diets containing $36 \%$ energy from fat with or without $1 \%$ cholesteyramine (CA) as a modulator of circulating cholesterol levels for $35 \mathrm{~d}$. It was revealed that the expression of lanosterol 14 $\alpha$-demethylase (CYP51) instead of 3-hydroxy-3-methylglutaryl (HMG)-CoA reductase mRNA expression was responsive to circulating cholesterol in hamsters fed hypercholesterolaemic diets. The high-fat diet increased circulating cholesterol and down-regulated CYP51, but not HMG-CoA reductase. The CA diet decreased cholesterol and increased CYP51 expression, but HMG-CoA reductase expression was not affected. The high-fat diet and CA diet altered the expression level of cholesterol, bile acids and lipid metabolism-associated genes (LDL receptor, cholesterol $7 \alpha$-hydroxylase (CYP7A1), liver X receptor (LXR) $\alpha$, and ATP-binding cassette subfamily $\mathrm{G}$ member 5/8 (ABCG5/8)) in the liver, which were significantly correlated with circulating cholesterol levels. Correlation analysis also showed that circulating cholesterol levels were regulated by LXR/retinoid X receptor and PPAR pathways in the liver. Using the hamster model, the present study provided additional molecular insights into the influence of circulating cholesterol on hepatic cholesterol metabolism pathways during hypercholesterolaemia.

Key words: Circulating cholesterol: CYP51: Hamsters: Hypercholesterolaemia

Hypercholesterolaemia is one of the major factors contributing to the onset and progression of CVD, the leading cause of death in industrialised societies ${ }^{(1)}$. Significant progress has been made in understanding of cholesterol metabolism since Goldstein \& Brown's seminal work ${ }^{(2)}$. Experimental and epidemiological studies have indicated that increased dietary intake of fat and cholesterol is a major contributor to hypercholesterolaemia in the Western world ${ }^{(3,4)}$. Dysregulation of cholesterol de novo synthesis or cholesterol deposition can also result in elevation in circulating cholesterol level ${ }^{(5,6)}$. 3-Hydroxy-3-methyl-glutaryl (HMG)-CoA reductase, the ratelimiting enzyme in the cholesterol synthesis pathway, and LDL receptor have been the main candidates of cholesterol metabolism in previous research ${ }^{(7-10)}$. Current understanding of cholesterol biosynthesis and deposition indicates three main pathways: (1) regulation of HMG-CoA reductase activity and levels; (2) regulation of excess intracellular non-esterified cholesterol through the activity of acyl-CoA:cholesterol

Abbreviations: ABCG5/8, ATP-binding cassette subfamily G member 5/8; CA, cholestyramine; CYP51, lanosterol 14 $\alpha$-demethylase; CYP7A1, cholesterol 7 $\alpha$-hydroxylase; $\mathrm{HF}$, high-fat; HF + CA, high-fat + cholestyramine; HMG, 3-hydroxy-3-methyl-glutaryl; IPA, Ingenuity Pathway Analysis; LXR $\alpha$, liver X receptor $\alpha$; RXR, retinoid X receptor; SREBP, sterol regulatory element-binding protein.

* Corresponding authors: Thomas T. Y. Wang, email Tom.Wang@ars.usda.gov; Liangli (Lucy) Yu, fax +1 301314 3313, email lyu5@umd.edu 
acyltransferase; and (3) regulation of plasma cholesterol levels via $L D L$ receptor-mediated uptake and HDL-mediated reverse transport ${ }^{(7)}$. In addition, pathways involved in bile acid metabolism and cholesterol absorption can also influence the circulating levels of cholesterol as well as its deposition ${ }^{(11,12)}$. However, the majority of previous studies have been concentrated on regulation and reduction of disease-state cholesterol levels; the molecular events related to changes in circulating cholesterol level are less understood.

The hamster is widely accepted as a suitable animal model for studying human cholesterol metabolism. The lipid profiles and susceptibility to dietary cholesterol of the golden Syrian hamster (Mesocricetus auratus) are similar to those of $\operatorname{man}^{(13-15)}$. In man and the hamster, LDL is the dominant lipoprotein, whereas HDL is the major plasma lipoprotein in other animal models (mouse, rat, dog and monkey) ${ }^{(16,17)}$. The hamster also exhibits similar cholesteryl ester transfer protein activity as man, which is absent in the rat ${ }^{(16-18)}$.

The present study aimed to gain more comprehensive understanding of relationship between circulating cholesterol levels and molecular effect in target tissues using the hamster model. A high-fat (HF) diet or the cholesterol-lowering drug cholestyramine (CA), which was given at $1 \%$, which is comparable with common prescription ${ }^{(19)}$, was used to modulate plasma cholesterol in the presnt study. Biochemical and molecular changes in cholesterol and lipid metabolism were determined to elucidate the relationship between plasma, liver and faecal cholesterol and lipid levels, as well as the regulation of the expression level of cholesterol- and lipid metabolism-related genes in the liver.

\section{Materials and methods}

\section{Animals and diets}

Male golden Syrian hamsters (approximately 80 g, LVG strain; Charles River) were given free access to water and rodent chow to acclimatise to the environment for 1 week prior to the experiment. For the experiment, hamsters were randomised into three groups of ten and fed one of the following: a HF diet ( $36 \%$ energy from fat diet with $1.4 \mathrm{~g}$ cholesterol $/ \mathrm{kg}$ diet), a HF diet containing CA (HF + CA) $36 \%$ energy from fat diet with $1.4 \mathrm{~g}$ cholesterol $/ \mathrm{kg}$ diet containing $1 \% \mathrm{CA}$ ), or chow (with $0.05 \mathrm{~g}$ cholesterol $/ \mathrm{kg}$ diet, $8728 \mathrm{C}$ Teklad Certified Rodent Diet; Harlan Laboratories, Inc.). Diets consisted of $18 \%$ protein, $45 \%$ carbohydrate, and $36 \%$ fat on an energy basis. The hamster and human HED (human equivalent dose) has a $k_{\mathrm{m}}$ factor of $5: 37^{(20)}$, and the $1 \% \mathrm{CA}$ used in hamsters (about $120 \mathrm{~g}$ ) is calculated based on $5 \mathrm{~g}$ for a $60 \mathrm{~kg}$ adult human. Diet compositions are listed in Table 1. The experimental diets were formulated and purchased from Research Diets. Animals (ten per group) were fed with the respective diet for 5 weeks with water available ad libitum. Food intake and body weight were recorded twice per week. The animal use and care protocol (protocol no. 10-014) for this study was reviewed and approved by the US Department of Agriculture (USDA), Agricultural Research Service, Beltsville Area Animal Care and Use Committee (BAACUC).

\section{Plasma and tissue collection}

Hamsters were subjected to $12 \mathrm{~h}$ fasting prior to killing and anaesthetised with $\mathrm{CO}_{2}$. Blood was collected by cardiac puncture with syringes previously rinsed with potassium EDTA solution $(15 \%, \mathrm{w} / \mathrm{v})$, and plasma was separated after centrifugation at $1300 \mathrm{~g}$ for $15 \mathrm{~min}$ at $4^{\circ} \mathrm{C}$. Livers and flank adipose tissues were collected, weighed, and one part of the tissue was immediately frozen in liquid $\mathrm{N}_{2}$ for analysis; the other part was preserved in RNALater RNA stabilisation solution (Ambion) and kept at $-80^{\circ} \mathrm{C}$.

\section{Plasma lipoprotein analysis}

Plasma lipoprotein cholesterol concentration was determined by size exclusion chromatography as previously described ${ }^{(21)}$. Briefly, an Agilent 1100 chromatograph was employed with a post-column derivatisation reactor, consisting of a mixing coil (1615-50 Bodman) in a temperature-controlled water jacket (Aura Industrials). A Hewlett-Packard (Agilent) HPLC pump 79851-A was used to deliver cholesterol reagent (Roche Diagnostics) at a flow rate of $0.2 \mathrm{ml} / \mathrm{min}$. Bovine cholesterol lipoprotein standards (Sigma Aldrich) were used to calibrate the signal on the basis of peak areas. A quantity of $15 \mu \mathrm{l}$ of plasma was injected via an Agilent 1100 auto sampler onto a Superose 6HR HPLC column (Pharmacia LKB Biotechnology). The lipoproteins were eluted with a $\mathrm{pH} 7 \cdot 0$ buffer solution containing $0 \cdot 15$ M-sodium chloride and $0.02 \%$ sodium azide at a flow rate of $0.5 \mathrm{ml} / \mathrm{min}$. Plasma lipoprotein concentration was calculated based on a standard curve.

\section{Hepatic lipid extraction}

Livers were excised and immediately frozen in liquid $\mathrm{N}_{2}$, and then stored at $-80^{\circ} \mathrm{C}$ prior to analysis. The extraction was a modification of the Folch method ${ }^{(22,23)}$. Approximately $0 \cdot 15$ $\mathrm{g}$ frozen liver were minced and transferred into a test tube. Then $6 \mathrm{ml}$ of chloroform-methanol $(2: 1, \mathrm{v} / \mathrm{v})$ were added, followed by a 2 min homogenisation and $30 \mathrm{~s}$ of sonication at $30 \%$ power level. Samples were then incubated with shaking for $2 \mathrm{~h}$ on a platform shaker. After incubation, 2 $\mathrm{ml}$ of double distilled water were added. Samples were then centrifuged at $500 \mathrm{~g}$ for $20 \mathrm{~min}$. After centrifugation, the bottom layer was carefully aspirated into a new test tube and incubated overnight. It was then filtered through a $0.22 \mu \mathrm{m}$ filter and dried by stream of $\mathrm{N}_{2}$. The dried lipid was weighed and re-dissolved in isopropanol with 10

$\%$ Triton X-100 and used for TAG and cholesterol analysis as described below.

\section{TAG, total cholesterol and non-esterified cholesterol in liver}

Hepatic TAG, total cholesterol and non-esterified cholesterol were enzymically determined using commercial kits (Triglyceride-SL, Genzyme Diagnostics PEI Inc.; Cholesterol E and Free Cholesterol E, Wako Chemicals) following manufacturers' protocols. 
Table 1. Diet content

\begin{tabular}{|c|c|c|c|c|c|c|}
\hline & \multicolumn{2}{|c|}{ High fat* } & \multicolumn{2}{|c|}{ High fat + cholestyramine ${ }^{*}$} & \multicolumn{2}{|c|}{ Chow† } \\
\hline & $g \%$ & Energy \% & $g \%$ & Energy \% & $g \%$ & Energy \% \\
\hline Protein & $21 \cdot 0$ & $18 \cdot 0$ & $21 \cdot 0$ & $18 \cdot 0$ & $24 \cdot 3$ & $32 \cdot 0$ \\
\hline Carbohydrate & $52 \cdot 0$ & $45 \cdot 0$ & $52 \cdot 0$ & $45 \cdot 0$ & $40 \cdot 2$ & 54.0 \\
\hline Fat & $19 \cdot 0$ & $36 \cdot 0$ & $19 \cdot 0$ & $36 \cdot 0$ & 4.7 & $14 \cdot 0$ \\
\hline Others & & & & & $23 \cdot 8$ & \\
\hline Total & & $100 \cdot 0$ & & $100 \cdot 0$ & & $100 \cdot 0$ \\
\hline \multicolumn{7}{|l|}{ Energy } \\
\hline $\mathrm{kcal} / \mathrm{g}$ & 4.58 & & 4.58 & & 3.00 & \\
\hline $\mathrm{kJ} / \mathrm{g}$ & $19 \cdot 16$ & & $19 \cdot 16$ & & 12.55 & \\
\hline Ingredient & g & kcal & g & kcal & g & kcal \\
\hline Casein & 222.0 & 888.0 & 222.0 & 888.0 & & \\
\hline DL-Methionine & 3.0 & $12 \cdot 0$ & 3.0 & $12 \cdot 0$ & & \\
\hline Maize starch & 453.0 & 1812.0 & 453.0 & 1812.0 & & \\
\hline Maltodextrin & $100 \cdot 0$ & 400.0 & $100 \cdot 0$ & $400 \cdot 0$ & & \\
\hline Sucrose & 0.0 & 0.0 & 0.0 & 0.0 & & \\
\hline Cellulose & 53.0 & 0.0 & 53.0 & 0.0 & & \\
\hline Maize oil & $100 \cdot 0$ & $900 \cdot 0$ & $100 \cdot 0$ & $900 \cdot 0$ & & \\
\hline Butter & 80.0 & $720 \cdot 0$ & 80.0 & $720 \cdot 0$ & & \\
\hline Menhaden oil & $20 \cdot 0$ & $180 \cdot 0$ & $20 \cdot 0$ & $180 \cdot 0$ & & \\
\hline Mineral mix & $45 \cdot 0$ & $40 \cdot 0$ & $45 \cdot 0$ & $40 \cdot 0$ & & \\
\hline Choline bitartrate & 3.0 & 0.0 & 3.0 & 0.0 & & \\
\hline Cholesterol & 1.5 & 0.0 & 1.5 & 0.0 & 0.05 & 0.0 \\
\hline Cholestyramine & 0.0 & 0.0 & $10 \cdot 9$ & 0.0 & 0.0 & 0.0 \\
\hline Total & $1080 \cdot 5$ & $4952 \cdot 0$ & 1091.4 & $4952 \cdot 0$ & $1000 \cdot 0$ & $3000 \cdot 0$ \\
\hline
\end{tabular}

* The high fat and high fat + cholestyramine diets were formulated and purchased from Research Diets.

† The chow diet was purchased from Harlan Laboratories.

\section{Faecal bile acids and cholesterol extraction}

Faecal bile acids and cholesterol were extracted using a modified protocol ${ }^{(24)}$. Faecal samples were collected during a $48 \mathrm{~h}$ period on days 33-35 after the initiation of the experiment. The samples were lyophilised, pulverised using a pestle and mortar, and weighed. A dried faecal sample $(0 \cdot 10 \mathrm{~g})$ was hydrolysed in $1.0 \mathrm{ml}$ of $2 \mathrm{M}-\mathrm{KOH}$ at $50^{\circ} \mathrm{C}$ for $5 \mathrm{~h}$. The cooled mixture was then extracted with two $6 \mathrm{ml}$ portions of diethyl ether to remove non-saponifiable components. Subsequently, $1 \mathrm{ml}$ of $20 \%$ sodium chloride followed by $0.2 \mathrm{ml}$ of 12 M-hydrochloric acid were added to the remaining mixture. The acidified mixture was extracted with two $6 \mathrm{ml}$ portions of diethyl ether and the pooled ether extracts were evaporated by $\mathrm{N}_{2}$ and redissolved in $0.5 \mathrm{ml}$ of ethanol. The samples were used for faecal bile acid and cholesterol determination as follows.

\section{Faecal bile acids and cholesterol analysis}

Faecal bile acid content was determined using a kit from Sigma-Aldrich as previously described ${ }^{(25)}$. $\beta$-Nicotinamide adenine dinucleotide hydrate (NAD), nitroblue tetrazolium chloride (NBT), diaphorase, $3 \alpha$-hydroxysterol dehydrogenase $(3 \alpha-H S D)$ and cholic acid were obtained from SigmaAldrich. NAD, NBT, diaphorase and $3 \alpha-H S D$ were prepared in $0.01 \mathrm{M}$-phosphate buffer at $\mathrm{pH} 7 \cdot 0$. The reaction mixture included $40 \mu \mathrm{l}$ of sample or standard with $4 \mu \mathrm{l}$ of Triton $\mathrm{X}-100,50 \mu \mathrm{l}$ of NAD $(2.5 \mathrm{~mm}), 50 \mu \mathrm{l}$ of NBT $(0.61 \mathrm{~mm})$, $50 \mu \mathrm{l}$ of diaphorase $(625 \mathrm{U} / \mathrm{l})$ and $50 \mu \mathrm{l}$ of $3 \alpha-\mathrm{HSD}(625$ $\mathrm{U} / \mathrm{l})$. The mixture was incubated for $60 \mathrm{~min}$ at ambient temperature, after which $40 \mu \mathrm{l}$ of phosphoric acid $(1.33 \mathrm{M})$ were added to stop the reaction. The absorbance of each reaction mixture was measured at $530 \mathrm{~nm}$. Cholic acid in ethanol was used to generate a standard curve and the amount of faecal bile acid obtained was determined using the standard curve. Cholesterol was determined by the same assay as for liver described above.

\section{Total RNA isolation, CDNA synthesis and gene expression analysis}

To determine the gene expression changes, liver preserved in RNALater was cut into 0.1 to $0.2 \mathrm{~g}$ pieces and homogenised using a Precellys 24 (Bertin Technologies). The RNeasy Mini Kit (Qiagen) was used for total RNA isolation from liver. The AffinityScript cDNASynthesis kit from Agilent was used to reverse transcribe complementary DNA. Real-time PCR was performed on an Applied Biosystems 7900HT Sequence Detection System using Fast SYBR Green Master Mix (Life Technologies). Primers used in this study are listed in Table 2. Relative mRNA expression levels were calculated using the $\Delta \mathrm{Ct}$ method $^{(26)}$. Glyceraldehyde-3-phosphate dehydrogenase (GAPDH) expression was used as the housekeeping gene for calculations.

\section{Pathway analysis and prediction}

Expression of cholesterol and bile acid metabolism genes in the $\mathrm{HF}$ and $\mathrm{HF}+\mathrm{CA}$ groups was subjected to core pathway analysis using the Ingenuity Pathway Analysis (IPA) software (Ingenuity Systems). Using IPA and its accompanying interaction database, a list of canonical pathways was determined based on core analysis of significance of changes in these genes. IPA also generated a network of the cholesterol and 
Table 2. Sequences of real-time PCR primers (SYBR Green primers)

\begin{tabular}{lll}
\hline Genes & Direction & \multicolumn{1}{c}{ Sequence $\left(5^{\prime}{ }^{\prime}{ }^{\prime}\right)$} \\
\hline GAPDH & Forward & GAACATCATCCCTGCATCCA \\
& Reverse & CCAGTGAGCTTCCCGTTCA \\
HMGCR & Forward & CGAAGGGTTGCAGTGATAAAGGA \\
& Reverse & GCCATAGTCACATGAAGCTTCTGTA \\
LDLR & Forward & TGAGGAACATCAACAGCATAAAC \\
& Reverse & ATCCTCCAGGCTGACCATCTGT \\
LXR $\alpha$ & Forward & ATTGCCATCAGCATCTTCTCT \\
& Reverse & GCATCCGTGGGACATCAGT \\
PPAR $\alpha$ & Forward & CTCCACCTGCAGAGCAACCA \\
& Reverse & CGTCAGACTCGGTCTTCTTGAT \\
ABCG5 & Forward & TGATTGGCAGCTATAATTTTGGG \\
& Reverse & GTTGGGTGCGATGGAAA \\
ABCG8 & Forward & TGCTGGCCATCATAGGGAG \\
& Reverse & TCCTGATTTCATCTTGCCACC \\
CYP7A1 & Forward & GGTAGTGTGCTGTTGTATAGGTTA \\
& Reverse & ACAGCCCAGGTATGGAATCAAC \\
CYP51 & Forward & GAGAGAAGTTTGCCTATGTGCC \\
& Reverse & TGTAACGGATTACTGGGTTTTCT \\
SREBP & Forward & GCGGACGCAGTCTGGG \\
& Reverse & ATGAGCTGGAGCATGTCTTCAAA \\
FAS & Forward & AGCCCCTCAAGTGCACAGTG \\
& Reverse & TGCCAATGTTTTCCCTGA \\
ACOX & Forward & TTACATGCCTTTGTTGTCCCTATC \\
& Reverse & CGGTAATTGTCCATCTTCAGGTA \\
\hline
\end{tabular}

GAPDH, glyceraldehyde 3-phosphate dehydrogenase; HMGCR, 3-hydroxy3-methyl-glutaryl-CoA reductase; $L D L R$, LDL receptor; $L X R$, liver $X$ receptor; $A B C G 5 / 8$, ATP-binding cassette subfamily G member 5/8; CYP7A1, cholesterol $7 \alpha$-hydroxylase; CYP51, lanosterol $14 \alpha$-demethylase; SREBP, sterol regulatory element-binding protein; FAS, fatty acid synthase; $A C O X$, acyl-CoA oxidase.

bile acid metabolism genes and upstream regulator genes, in which their potential interactions were depicted.

\section{Statistical analysis}

All end point assays for each sample were conducted in triplicate and the average was used for group analysis, data for each treatment group are presented as means with their standard errors. Significance level of differences in means was detected using one-way ANOVA and Tukey's test. Correlation between plasma lipoproteins, hepatic lipid, cholesterol, and bile acids, faecal cholesterol and bile acids, and hepatic gene expression levels were calculated using the two-tailed Pearson correlation method. Linear regression analysis of ATP-binding cassette subfamily $G$ member 5 (ABCG5), ATP-binding cassette subfamily $G$ member 8 (ABCG8), cholesterol $7 \alpha$-hydroxylase (CYP7A1), hepatic lipid content, and faecal bile acids, and polynomial regression analysis of lanosterol $14 \alpha$-demethylase (CYP51), and total lipoprotein and hepatic cholesterol, were performed using Graphpad Prism 6 (2012; Graphpad Software). Statistics were analysed using IBM SPSS Statistics 19.0 (2010; IBM Corporation). Statistical significance was defined at $P \leq 0 \cdot 05$.

\section{Results}

\section{Food intake and body weight}

No differences in body weight were observed among the diet groups throughout the 5-week feeding period (Fig. 1(A)). Food intake was significantly different among the three diet groups. The chow diet group had the highest food intake and the HF group consumed the least (Fig. 1(B)). However, due to the higher fat content, HF groups recorded higher energy intake. The $\mathrm{HF}+\mathrm{CA}$ group had the highest energy intake of 37.97 (SE 2.55) kcal/d (158.87 (SE 10.67) kJ/d), and energy intake for the HF group was 31.68 (SE 2.43) $\mathrm{kcal} / \mathrm{d}(132.55$ (SE 10.17 kJ/d), while 29.07 (SE $2.17 \mathrm{kcal} / \mathrm{d}$ $(121.63$ (SE 9.08) kJ/d) for the chow group was the least despite the higher food intake. The HF group had the highest liver weight, and the HF + CA group had a liver weight similar to that of the chow diet group (Fig. 1(C)). There were no differences in weight of adipose tissue across the diet groups (Fig. 1(D)).

\section{Plasma lipoprotein cholesterol content}

Consumption of the HF diet significantly elevated VLDL (407\%), LDL (394\%), HDL (35\%) and total lipoprotein levels $(85 \%)$ in hamster plasma compared with the chow diet group (Fig. 2). Animals on the $\mathrm{HF}+\mathrm{CA}$ diet showed significantly lower VLDL (90 \%), LDL (87\%), HDL (34\%) and total lipoprotein $(54 \%)$ than animals on the HF diet (Fig. 2). Our results showed that $1 \%$ CA completely reversed the HF diet-induced increase of lipoprotein levels, and lowered VLDL, LDL, HDL and total lipoprotein levels back to the same levels as those of the chow diet group (Fig. 2).

\section{Cholesterol and lipid content of liver}

In animals fed the HF diet, hepatic cholesteryl esters and nonesterified cholesterol increased 465 and $118 \%$, respectively, compared with those of animals on the chow diet, and cumulatively resulted in a $248 \%$ increase in hepatic total cholesterol (Fig. 3). Hepatic cholesteryl esters and non-esterified cholesterol were lower in the $\mathrm{HF}+\mathrm{CA}$ group $(57$ and $68 \%$, respectively) compared with the HF group (Fig. 3(A) and (B)). Overall, the total lipid content in the liver of HF diet animals was $88 \%$ higher than those on the chow diet, and total lipid in the liver of the $\mathrm{HF}+\mathrm{CA}$ group was $41 \%$ lower than $\mathrm{HF}$ diet-fed animals, and at the same level as that of chow diet animals (Fig. 3(D)). Hepatic TAG level in the HF diet group increased $40 \%$ compared with that of the chow diet group, while the $\mathrm{HF}+\mathrm{CA}$ group showed a $14 \%$ reduction in TAG level, although the differences did not reach statistical significance (Fig. 3(E)). Hepatic bile acid was $68 \%$ lower in the $\mathrm{HF}+\mathrm{CA}$ group than that of the HF group, which was similar to the bile acid level in the chow diet group (Fig. 3(F)).

\section{Cholesterol and bile acid content of faeces}

A significant increase in faecal cholesterol was observed in HF groups compared with the chow diet group. There was no significant difference between the HF group and the $\mathrm{HF}+\mathrm{CA}$ group in excretion of faecal non-esterified and total cholesterol (Fig. 4(A) and (B)). Compared with animals on the HF diet, the $\mathrm{HF}+\mathrm{CA}$ group showed a $183 \%$ increase in bile acid excretion, while there were no differences in faecal bile acid levels between the HF and chow groups (Fig. 4(C)). 

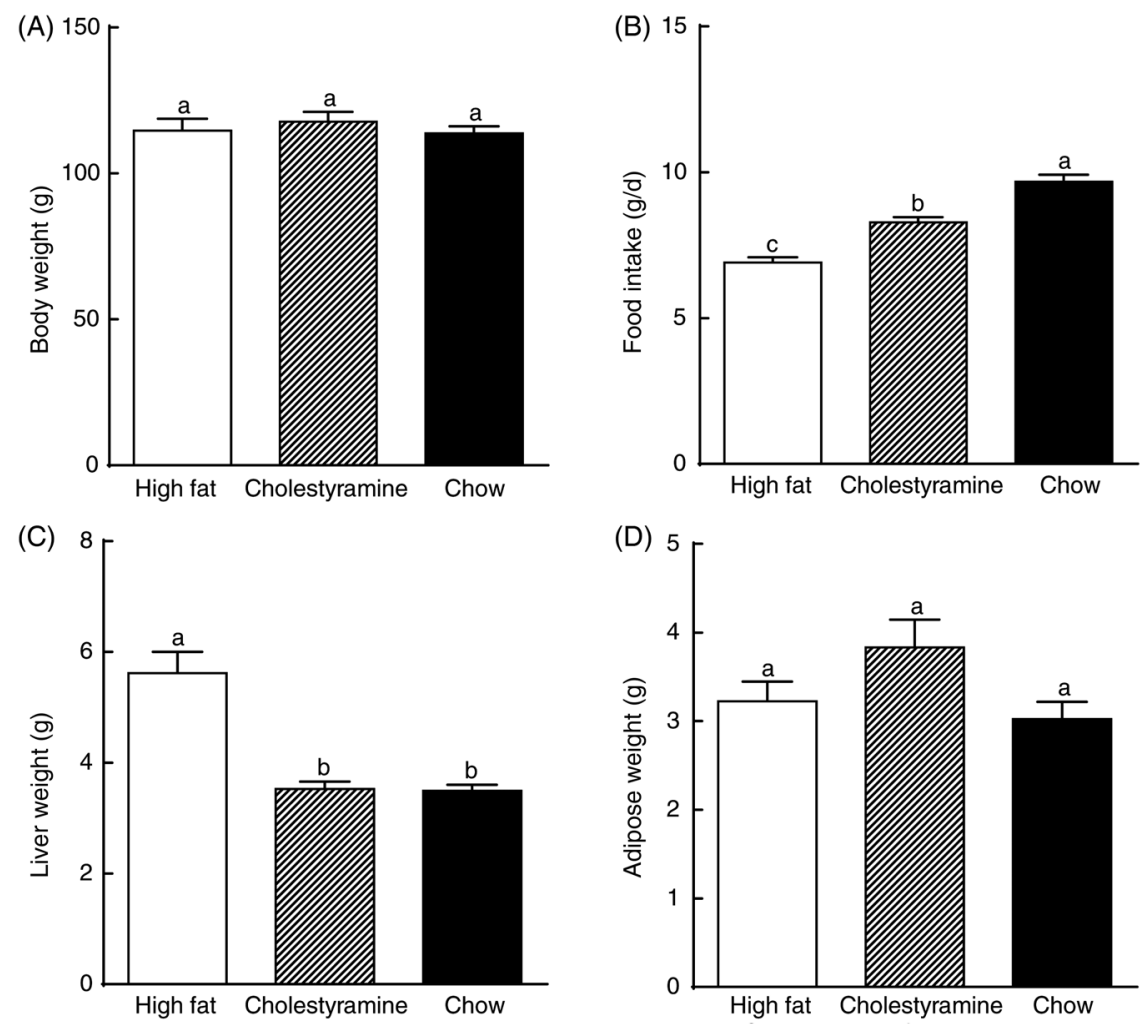

Fig. 1. Food intake, and body and tissue weights. Hamster body (A), liver (C) and adipose (D) weights after 5-week feeding period. Food intake (B) was calculated as average daily intake. Values are means $(n 10)$, with standard errors represented by vertical bars. ${ }^{\text {a,b,c }}$ Mean values with unlike letters were significantly different $(P \leq$ $0.05)$.
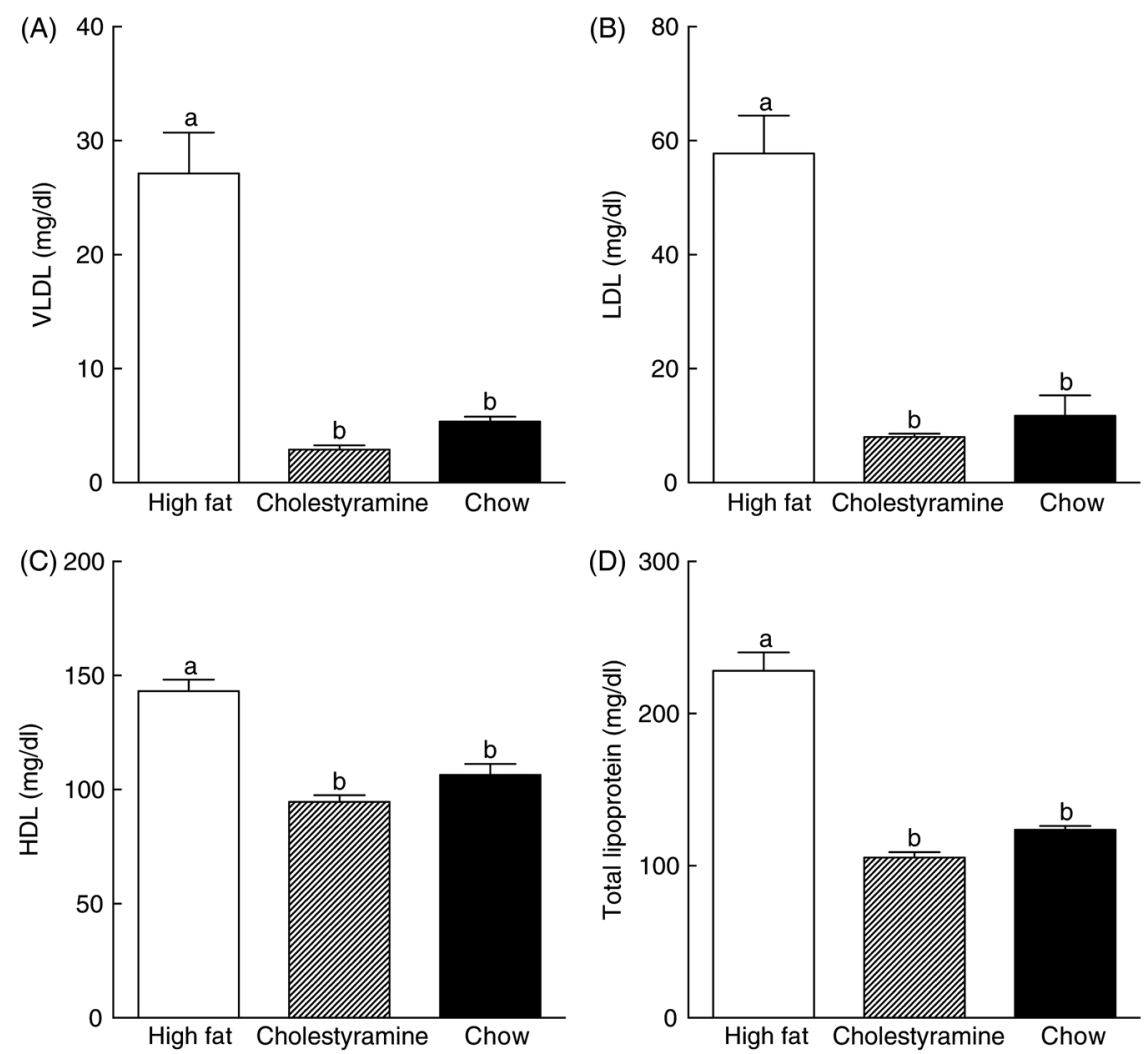

Fig. 2. Effects of cholestyramine supplementation on plasma lipoprotein cholesterol levels. Hamster plasma from different diet groups was harvested and plasma lipoprotein cholesterol concentrations were determined by size exclusion chromatography as described in Materials and methods. (A) VLDL, (B) LDL, (C) HDL and (D) total lipoprotein. Values are means $(n 10)$, with standard errors represented by vertical bars. ${ }^{\mathrm{a}, \mathrm{b}}$ Mean values with unlike letters were significantly different $(P \leq$ 0.05). To convert $\mathrm{mg} / \mathrm{dl}$ to $\mathrm{mmol} / \mathrm{l}$, multiply by 0.0259 . 


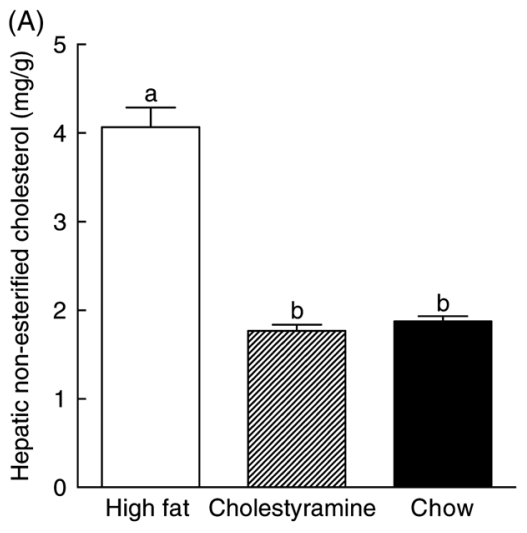

(C)

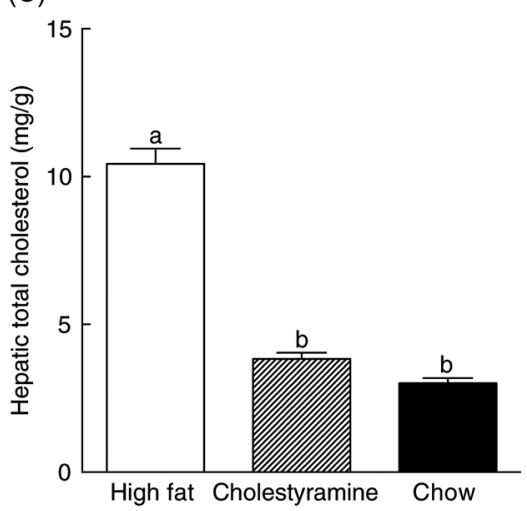

(E)

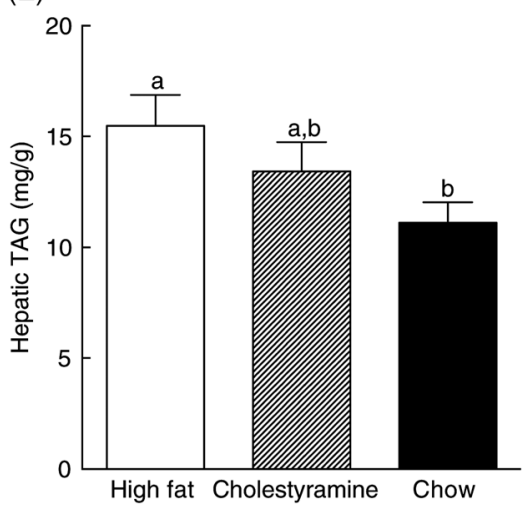

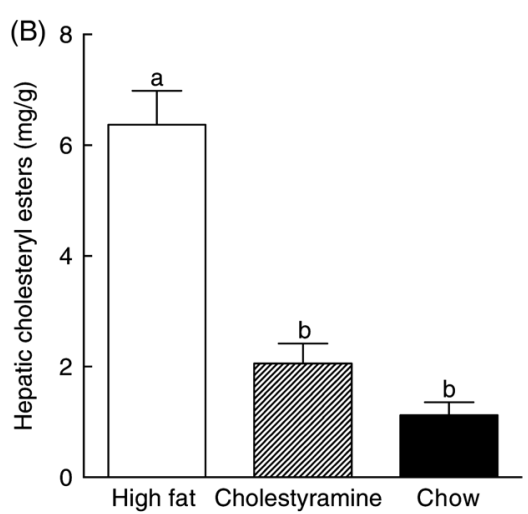
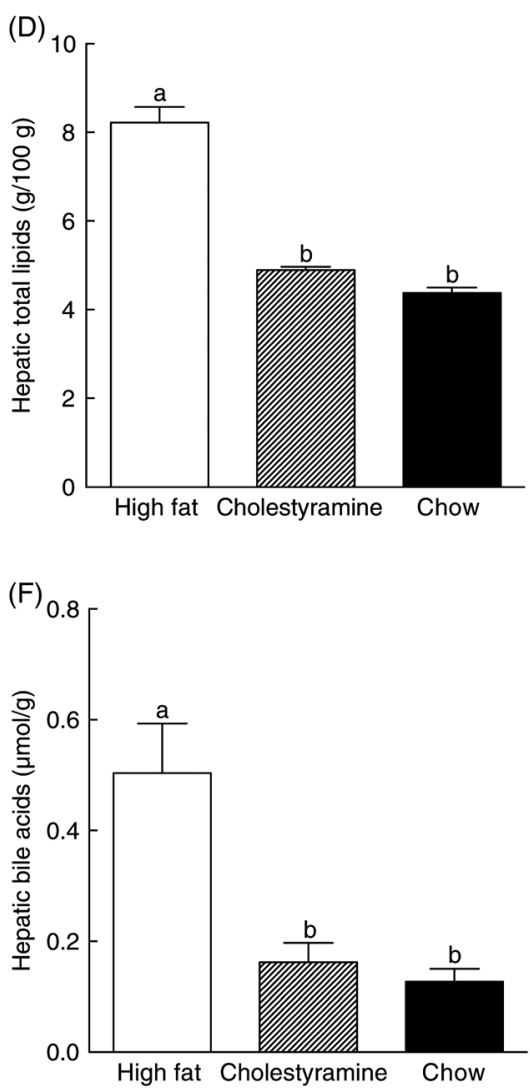

Fig. 3. Effects of cholestyramine supplementation on hepatic cholesterol, TAG and bile acid levels. Livers were harvested from animals on different diets and hepatic lipid extracted and enzymically determined as described in Materials and methods. (A) Hepatic non-esterified cholesterol, (B) hepatic cholesteryl esters, (C) hepatic total cholesterol, (D) hepatic total lipids, $(E)$ hepatic TAG and (F) hepatic bile acids. Values are means $(n 10)$, with standard errors represented by vertical bars. ${ }^{\text {a,b }}$ Mean values with unlike letters were significantly different $(P \leq 0.05)$.

\section{Relative expression of genes related to cholesterol and bile acid metabolism and ingenuity pathway analysis}

To elucidate the metabolic pathways affected by changes in circulating cholesterol levels, expression of hepatic cholesterol, bile acid and fatty acid metabolism genes were determined. There were no differences in the LDL receptor mRNA expression levels between the HF group and the chow group, while the $\mathrm{HF}+\mathrm{CA}$ group had a $126 \%$ increase in LDL receptor expression (Fig. 5). Compared with the chow diet group, the hepatic mRNA level of the HMG-CoA reductase in the HF group, with or without CA, decreased about $45 \%$ (Fig. 5). However, due to the variance between individual animals, the change did not reach statistical significance. Another rate- limiting enzyme in cholesterol synthesis, CYP51, was downregulated $88 \%$ in the $\mathrm{HF}$ group, while a $1280 \%$ up-regulation was observed in the HF + CA group (Fig. 5).

Liver X receptor (LXR) $\alpha$ and PPAR $\alpha$ are key factors involved in the regulation of cholesterol metabolism ${ }^{(27,28)}$. $L X R \alpha$ mRNA expression was up-regulated by $45 \%$ in the $\mathrm{HF}+\mathrm{CA}$ group, and the HF and chow diet groups showed similar expression levels (Fig. 5). PPAR $\alpha$ expression was suppressed by $26 \%$ by the HF diet, and the suppression was reversed in the $\mathrm{HF}+\mathrm{CA}$ group (Fig. 5).

CYP7A1 was increased by $855 \%$ in the $\mathrm{HF}+\mathrm{CA}$ group (Fig. 5), and the HF and chow diets showed similar expression levels of CYP7A1. The HF diet significantly elevated both 

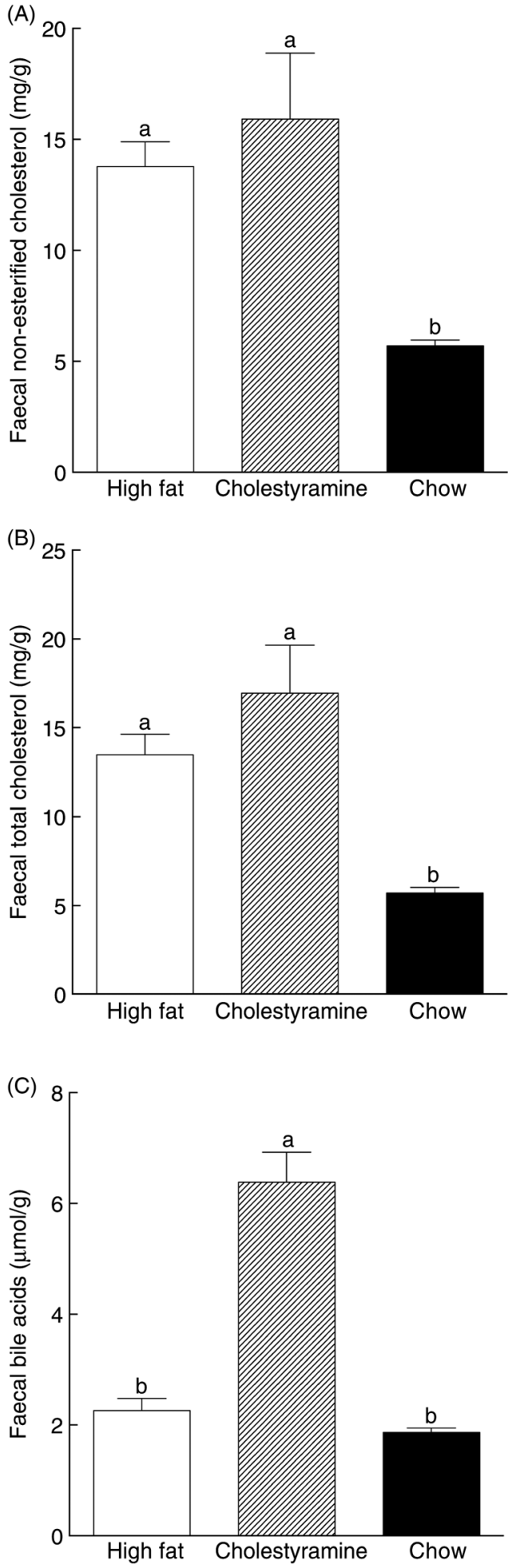

Fig. 4. Effects of cholestyramine supplementation on cholesterol and faecal bile acid levels. Faecal samples were collected for $2 \mathrm{~d}$ for animals on different diets and faecal bile acid and total cholesterol were extracted and determined as described in Materials and methods. (A) Faecal non-esterified cholesterol, (B) faecal total cholesterol and (C) faecal bile acids. Values are means ( $n 10)$, with standard errors represented by vertical bars. ${ }^{a, b}$ Mean values with unlike letters were significantly different $(P \leq 0.05)$.

ABCG5 and ABCG8 mRNA expression by 295 and $158 \%$, respectively (Fig. 5). Animals in $\mathrm{HF}+\mathrm{CA}$ group expressed significantly lower levels of ABCG5 (89\%) and ABCG8 (60\%)
mRNA as compared with that of the HF diet animals (Fig. 5), which were back to the same level as that of the chow diet group.

Animals on the HF diet had $98 \%$ higher hepatic sterol regulatory element-binding protein (SREBP)-1c expression than animals on the chow diet (Fig. 5). Expression of SREBP-1c in the $\mathrm{HF}+\mathrm{CA}$ group was $45 \%$ lower and reduced to the same level as that of the chow diet group (Fig. 5). The mRNA levels of fatty acid synthase and acyl-CoA oxidase were not affected by the different diets (Fig. 5).

IPA of the cholesterol and bile acid metabolism genes identified that reduction in circulating cholesterol activated multiple canonical pathways including LXR/retinoid X receptor (RXR) $(P<0 \cdot 001)$, farnesoid $\mathrm{X}$ receptor $/ \mathrm{RXR}(P<0 \cdot 001)$, thyroid hormone receptor/RXR $(P<0.001)$ and hepatic cholestasis $(P<0.001)$, and predicted $\operatorname{RXR} \alpha(P=0 \cdot 001)$, LDL receptor $(P=0.005)$, Niemann-Pick C1 protein (NPC1) $(P=0.007)$, $\operatorname{LXR} \beta(P=0 \cdot 010)$, and signal transducer and activator of transcription 1 (STAT1) $(P=0 \cdot 011)$ as upstream regulators (Fig. 6). The pathway analysis also determined that inflammatory response $(P<0.038)$, CVD $(P<0.002)$ and metabolic disease $(P=0 \cdot 010)$ were presented in the HF animals.

\section{Correlation between plasma lipoprotein, hepatic and faecal cholesterol and hepatic gene expression}

Correlations of plasma lipoprotein concentration, hepatic lipid, cholesterol and bile acids, faecal cholesterol and bile acids and hepatic gene expression levels were examined to understand the relationship between molecular and physiological changes resulting from different circulating cholesterol levels (Tables 3 to 5). Plasma total lipoprotein $(r-0.409)$ and HDL $(r-$ $0 \cdot 525)$ were negatively correlated with LDL receptor expression, while bile acids $(r 0.492)$ excretion correlated with LDL receptor expression level. In the cholesterol synthesis pathway, HMG-CoA reductase expression did not correlate with any physiological changes measured in this study; and CYP51 was negatively correlated with liver weight $(r-0 \cdot 444)$, plasma lipoproteins $(r-0.541)$ and hepatic cholesterol $(r-0.427)$. LXR $\alpha$ and PPAR $\alpha$, the upstream regulators in cholesterol metabolism and synthesis, were also negatively correlated with plasma lipoproteins $(r-0.559$ and $r-0.410$, respectively), with $P P A R \alpha$ negatively correlated with hepatic cholesterol $(r-0.406)$ and positively with faecal bile acids $(r 0.643)$, and LXR $\alpha$ negatively correlated with hepatic bile acids $(r-$ $0.432)$ and positively with faecal bile acids $(r 0.472)$. In the cholesterol excretion pathway, CYP7A1 expression was correlated with adipose tissue $(r 0.446)$, plasma lipoproteins $(r-$ $0 \cdot 523)$, hepatic non-esterified cholesterol $(r-0.420)$ and faecal cholesterol $(r-0.516)$, and most significantly faecal bile acids (r0.824). ABCG5 and ABCG8 showed correlation with liver weight $(r 0.470$ and $r 0.378)$, plasma lipoproteins $(r 0.696$ and $r 0.508)$, hepatic cholesterol $(r 0.763$ and $r 0.693)$ and TAG (r0.409 and $r 0.437)$. Additionally, ABCG5 also correlated with hepatic and faecal bile acids $(r 0.368$ and $r-$ $0 \cdot 477)$. In the fatty acid metabolism pathway, SREBP-1c was correlated with liver weight $(r 0 \cdot 392)$, plasma lipoproteins $(r$ $0 \cdot 497)$ and hepatic cholesterol (r0.519). Fatty acid synthase 


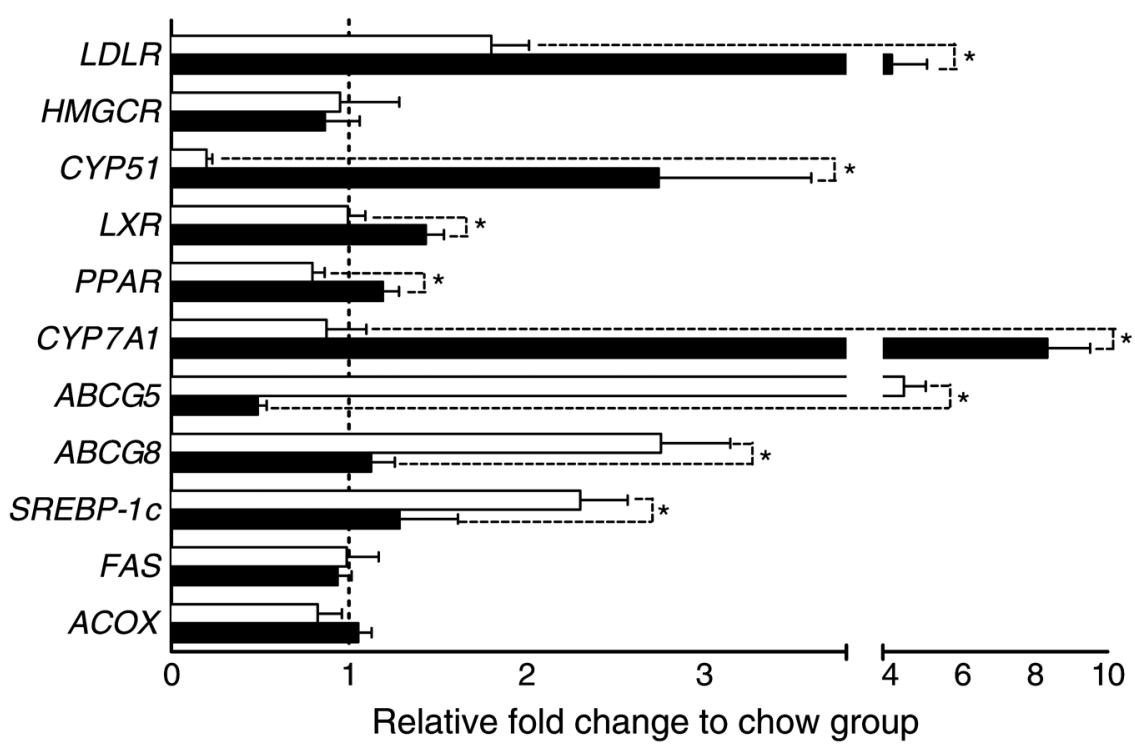

Fig. 5. Effects of cholestyramine supplementation on hepatic mRNA expression levels. Livers were harvested from animals on different diets; total mRNA extracted and mRNA level were determined using real-time PCR as described in Materials and methods. Results are expressed as relative expression levels to the chow diet group (-). Values are means $(n 10)$, with standard errors represented by horizontal bars. * Mean values were significantly different from each other $(P \leq 0.05)$. $\square$,

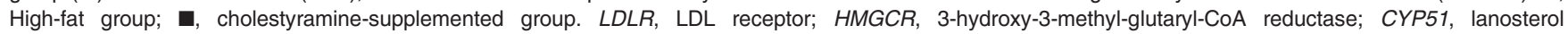

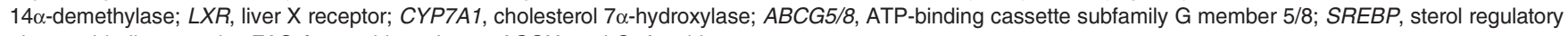
element-binding protein; FAS, fatty acid synthase; ACOX, acyl-CoA oxidase.

did not show any significant correlation with any physiological changes in this study, and acyl-CoA oxidase was correlated with liver weight $(r-0 \cdot 374)$, VLDL $(r-0 \cdot 386), \operatorname{HDL}(r-$ $0.455)$ and total lipoprotein $(r-0.433)$, and hepatic bile acids $(r-0 \cdot 392)$.

\section{Regression analysis of hepatic lipid concentration, total lipoprotein concentration, faecal bile acids concentration and selected hepatic gene expression}

Regression analysis was performed to determine the relationship between concentration changes of hepatic lipids, total

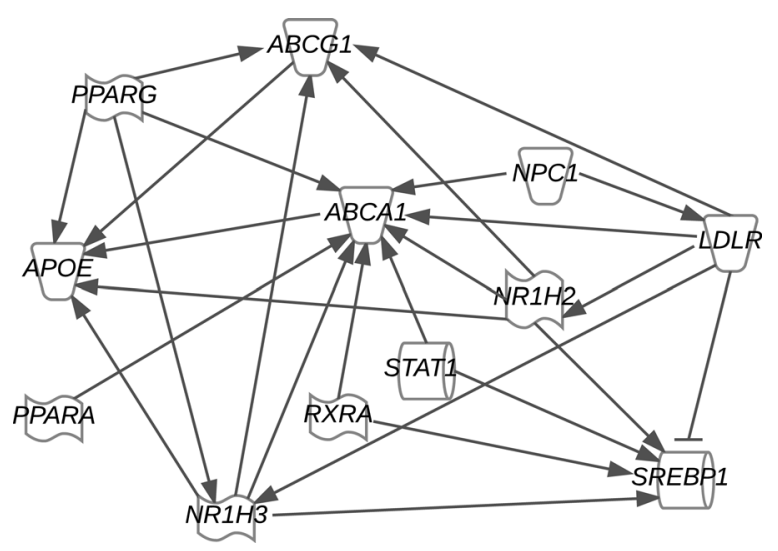

Fig. 6. Ingenuity Pathway Analysis (IPA) of cholesterol and bile acid metabolism genes. Gene expression data were analysed using IPA core analysis and a network was generated. $A B C G 1$, ATP-binding cassette subfamily $G$ member 1; PPARG, PPAR- $\gamma$; NPC1, Niemann-Pick C1; ABCA1, ATP-binding cassette subfamily A member 1; LDLR, LDL receptor; APOE, apoE; NR1H2, gene for liver $X$ receptor- $\beta$; STAT1, signal transducer and activator of transcription 1; PPARA, PPAR- $\alpha$; RXRA, retinoid $\mathrm{X}$ receptor; SREBP1, sterol regulatory element-binding protein $1 ; N R 1 H 3$, for gene for liver $\mathrm{X}$ receptor- $\alpha$. lipoprotein and faecal bile acid, and hepatic gene expression levels. We focused on representative hepatic genes $A B C G 5 /$ 8, CYP7A1 and CYP51. There was a linear increase of $A B C G 5$ and $A B C G 8$ mRNA levels with hepatic lipid concentration $\left(R^{2} 0.7979\right.$ and 0.6828 , respectively; Fig. 7(A) and (B)). Increased faecal bile acid was associated with increased CYP7 11 mRNA levels $\left(R^{2}\right.$ 0.6781; Fig. 7(C)). CYP51 mRNA levels, linear regression to total lipoprotein concentration showed an $R^{2}$ of $0.2926(P=0.002)$, to hepatic total cholesterol showed an $R^{2}$ of $0.1823(P=0.0186)$, and an $R^{2}$ of $0.1559(P=0.069)$ to hepatic bile acids.

\section{Discussion}

This study identified CYP51 as a gene responsive to changes in circulating cholesterol induced by the HF diet and CA in hamsters. CYP51 converts lanosterol to cholesterol, and is a critical enzyme in the de novo synthesis of cholesterol. Increased circulating cholesterol induced by the HF diet significantly lowered CYP51 mRNA expression in the liver (Fig. 5), which was consistent with a previous study using a Sprague-Dawley rat model $^{(29)}$. In contrast, decreased circulating cholesterol induced by CA significantly up-regulated CYP51 expression in the liver (Fig. 5). Previous studies mostly focused on HMG-CoA reductase's role in cholesterol regulation, but discrepancy existed in the literature, which may result from the different models (human, mouse and rat) used in these studies ${ }^{(10,30,31)}$. In the present study, HMG-CoA reductase, the classic rate-limiting enzyme involved in cholesterol synthesis pathway upstream of CYP51, was not affected by the HF or HF + CA diet, and independent of circulating cholesterol levels (Fig. 5). We also observed that CYP51 expression levels were correlated with liver weight, plasma VLDL, LDL, HDL, and hepatic non- 
Table 3. Correlations between hepatic gene expression and liver, adipose weight and plasma lipoproteins

\begin{tabular}{|c|c|c|c|c|c|c|}
\hline & Liver weight & Adipose weight & VLDL & LDL & $\mathrm{HDL}$ & Total lipoprotein \\
\hline$L D L R$ & -0.356 & -0.077 & -0.371 & -0.247 & $-0.525^{\star \star}$ & $-0.409^{\star}$ \\
\hline HMGCR & -0.173 & -0.123 & -0.174 & -0.120 & -0.233 & -0.188 \\
\hline CYP51 & $-0.444^{*}$ & 0.014 & $-0.468^{\star *}$ & $-0.371^{*}$ & $-0.658^{* *}$ & $-0.541^{* *}$ \\
\hline$L X R \alpha$ & $-0.453^{*}$ & 0.106 & $-0.538^{* *}$ & $-0.414^{*}$ & $-0.618^{\star *}$ & $-0.559^{\star *}$ \\
\hline$P P A R \alpha$ & -0.336 & 0.170 & $-0.401^{\star}$ & -0.354 & $-0.396^{\star}$ & $-0.410^{\star}$ \\
\hline CYP7A1 & -0.347 & $0.446^{*}$ & $-0.465^{\star \star}$ & $-0.455^{\star}$ & $-0.526^{\star *}$ & $-0.523^{\star \star}$ \\
\hline ABCG5 & $0.470^{\star *}$ & -0.312 & $0.580^{\star *}$ & $0.701^{\star *}$ & $0.620^{\star *}$ & $0.696^{\star *}$ \\
\hline ABCG8 & $0.378^{\star}$ & -0.269 & $0.420^{*}$ & $0.518^{\star \star}$ & $0.446^{\star}$ & $0.508^{\star \star}$ \\
\hline SREBP1 & $0.392^{*}$ & 0.023 & $0.436^{*}$ & $0.384^{*}$ & $0.554^{* *}$ & $0.497^{\star *}$ \\
\hline FAS & 0.297 & 0.185 & 0.200 & -0.087 & 0.197 & 0.086 \\
\hline ACOX & $-0.374^{*}$ & 0.070 & $-0.386^{\star}$ & -0.359 & $-0.455^{\star}$ & $-0.433^{*}$ \\
\hline
\end{tabular}

LDLR, LDL receptor; HMGCR, 3-hydroxy-3-methyl-glutaryl-CoA reductase; CYP51, lanosterol 14 $\alpha$-demethylase; $L X R$, liver X receptor; CYP7A1, cholesterol 7 $\alpha$-hydroxylase; $A B C G 5 / 8$, ATP-binding cassette subfamily G member 5/8; SREBP, sterol regulatory element-binding protein; FAS, fatty acid synthase; ACOX, acyl-CoA oxidase.

* Significant correlation $(P<0.05$; two-tailed $)$.

** Significant correlation $(P<0.01$; two-tailed).

esterified cholesterol and cholesteryl ester (Tables 3 and 4). Previous research characterised that CYP51 can respond to circulating cholesterol through SREBP, which are regulated by a lipid-sensor mechanism ${ }^{(32)}$. Three clustered regulatory elements (GC box, cAMP-response elements, and sterol regulatory element) were found in the proximal promoter region of CYP51. CYP51 was shown to also respond to the AMP-dependent signalling pathway in the absence of mature SREBP and a single cAMP-response element is sufficient to mediate an immediate early transactivation of the CYP51 gene ${ }^{(33)}$. Based on our results, CYP51 appeared to be more sensitive to fluctuation of circulating cholesterol. Induction of CYP51 in HF + CA animals reflects that liver cells can sense decreases in cholesterol levels and up-regulate CYP51 to compensate for this change. Induction of CYP51 might thus significantly increase de novo cholesterol synthesis providing sufficient substrate, namely lanosterol, without the involvement of HMG-CoA reductase. Hence, CYP51 may deserve more attention as a potential target in terms of hypercholesterolaemia treatments, and administration of CYP51 inhibitor, in combination with HMG-CoA reductase inhibitor, may achieve a further reduction in disease-state circulating and hepatic cholesterol levels.

Changes in hepatic lipid content and faecal bile acid concentration and changes in $A B C G 5 / 8$ and CYP7A1 mRNA levels, respectively, could be fitted to a linear model. This suggested a direct relationship between the gene expression and hepatic lipid and faecal bile acid levels. Increases in the excretion of bile acids in $\mathrm{HF}+\mathrm{CA}$ animals led to de-repression of CYP7A1 expression in the liver, which is consistent with previous studies ${ }^{(34)}$. In contrast, changes in CYP51 mRNA levels could not be fitted to a linear model with plasma lipoprotein levels, hepatic total cholesterol or bile acids. A higher-order polynomial model was required to get a better fit. Though CYP51 showed significant correlation with plasma lipoprotein concentration, hepatic lipid content and cholesterol level, none of them was a dominant factor in the regression analysis. These results indicated that the regulation of CYP51 expression may be due to multiple factors. CYP51 was identified as an immediate early response gene in the SREBP regulation pathway ${ }^{(33)}$. Previous reports also showed up-regulation of CYP51 by phytochemical or viscous carbohydrate polymer treatments ${ }^{(3,4)}$. Others also reported that the regulation of CYP51 expression may be subject to multiple pathways and upstream regulators ${ }^{(32,33,35)}$. Our results were consistent with this notion but further study is needed to elucidate the precise mechanisms.

CA is known to bind bile acids and increase their excretion, but faecal cholesterol level has not usually been reported. A previous study reported that CA treatment induced an increase

Table 4. Correlations between hepatic gene expression and hepatic lipid, cholesterol and bile acids

\begin{tabular}{|c|c|c|c|c|c|c|}
\hline & Lipid content & Total cholesterol & Non-esterified cholesterol & Cholesteryl ester & TAG & Bile acids \\
\hline$L D L R$ & -0.194 & -0.215 & -0.321 & -0.096 & -0.146 & -0.116 \\
\hline HMGCR & -0.206 & -0.190 & -0.138 & -0.267 & -0.096 & -0.269 \\
\hline CYP51 & $-0.437^{\star}$ & $-0.427^{\star}$ & $-0.490^{\star *}$ & $-0.449^{\star}$ & -0.164 & -0.332 \\
\hline$L X R \alpha$ & -0.123 & -0.271 & -0.245 & -0.353 & 0.216 & $-0.432^{*}$ \\
\hline$P P A R \alpha$ & $-0.456^{\star}$ & $-0.406^{\star}$ & $-0.545^{\star *}$ & -0.332 & -0.013 & -0.240 \\
\hline CYP7A1 & -0.312 & -0.346 & $-0.420^{\star}$ & -0.223 & -0.182 & $-0 \cdot 154$ \\
\hline ABCG5 & $0.893^{\star *}$ & $0.763^{\star \star}$ & $0.836^{\star *}$ & $0.628^{* *}$ & $0.409^{*}$ & $0.368^{*}$ \\
\hline$A B C G 8$ & $0.826^{\star \star}$ & $0.693^{\star *}$ & $0.842^{* *}$ & $0.478^{* *}$ & $0.437^{\star}$ & 0.167 \\
\hline SREBP1 & $0.551^{\star *}$ & $0.519^{\star \star}$ & $0.615^{\star \star}$ & $0.361^{*}$ & 0.312 & 0.079 \\
\hline FAS & -0.135 & -0.042 & 0.048 & -0.188 & 0.105 & -0.248 \\
\hline$A C O X$ & -0.243 & -0.251 & -0.200 & -0.321 & -0.049 & $-0.392^{*}$ \\
\hline
\end{tabular}

$L D L R$, LDL receptor; HMGCR, 3-hydroxy-3-methyl-glutaryl-CoA reductase; CYP51, lanosterol 14 $\alpha$-demethylase; $L X R$, liver X receptor; CYP7A1, cholesterol 7 $\alpha$-hydroxylase; $A B C G 5 / 8$, ATP-binding cassette subfamily G member 5/8; SREBP, sterol regulatory element-binding protein; FAS, fatty acid synthase; ACOX, acyl-CoA oxidase.

* Significant correlation $(P<0.05$; two-tailed).

** Significant correlation $(P<0.01$; two-tailed). 
Table 5. Correlation between hepatic gene expression and faecal cholesterol and bile acids

\begin{tabular}{lccc}
\hline & Total cholesterol & Non-esterified cholesterol & Bile acids \\
\hline LDLR & 0.173 & 0.120 & $0.492^{*}$ \\
HMGCR & -0.390 & -0.391 & -0.263 \\
CYP51 & 0.082 & 0.017 & 0.395 \\
LXR $\alpha$ & 0.103 & 0.084 & $0.472^{*}$ \\
PPAR $\alpha$ & 0.121 & 0.062 & $0.643^{\star *}$ \\
CYP7A1 & $0.516^{*}$ & $0.484^{*}$ & $0.824^{* *}$ \\
ABCG5 & -0.084 & -0.005 & $-0.477^{*}$ \\
ABCG8 & 0.019 & 0.095 & -0.316 \\
SREBP1 & -0.048 & 0.044 & -0.363 \\
FAS & -0.009 & 0.008 & -0.076 \\
ACOX & -0.099 & -0.092 & 0.041 \\
\hline
\end{tabular}

LDLR, LDL receptor; HMGCR, 3-hydroxy-3-methyl-glutaryl-CoA reductase; CYP51,

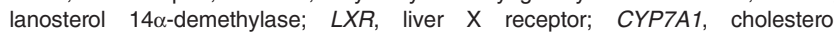
$7 \alpha$-hydroxylase; $A B C G 5 / 8$, ATP-binding cassette subfamily G member $5 / 8$ $S R E B P$, sterol regulatory element-binding protein; FAS, fatty acid synthase; $A C O X$, acyl-CoA oxidase.

* Significant correlation $(P<0.05$; two-tailed $)$

** Significant correlation $(P<0.01$; two-tailed $)$.

in faecal cholesterol excretion in a mouse model ${ }^{(36)}$. In our study, using the hamster as a model, the HF diet was shown to induce an increase of faecal cholesterol excretion, while faecal cholesterol (non-esterified form or esters) was not affected by CA treatment (Fig. 4(A) and (B)). This result confirms a previous study of dietary CA in hamsters ${ }^{(37)}$. Additional studies are needed to confirm these observations in human subjects.

In the present study, supplementation of $1 \% \mathrm{CA}$ in a $\mathrm{HF}$ diet for 5 weeks was shown to significantly reduce circulating lipoprotein, hepatic cholesterol and lipid levels to a level similar to animals on a chow diet. The recommended daily dose of CA is $4-8 \mathrm{~g}$ or about 0.4 to $0.8 \%$ in the approximate $958 \mathrm{~g}$ average food intake by the US population ${ }^{(38)}$. Thus, $1 \%$ CA in hamster diets is comparable with that suggested for humans. The $1 \%$ CA supplementation was able to reduce about $87 \%$ VLDL + LDL in hamsters on a HF diet for 5 weeks (Fig. 2). Suckling et al. ${ }^{(39)}$ conducted a 1 -week study and determined that $2 \%$ CA achieved a $55 \%$ decrease in VLDL + LDL in hamsters. Our results suggest that length of treatment might be as important a variable as dose.

$\mathrm{CA}$ in the HF diet reduced hepatic non-esterified cholesterol and cholesteryl esters, as well as bile acid, to a similar level to the chow diet group (Fig. 3). Previous studies have shown that CA, psyllium and hydroxyl-propylmethylcellulose feeding increased bile acid excretion and reduced non-esterified and esterified hepatic cholesterol ${ }^{(3,37)}$. Animals consuming CA excreted significantly more bile acids, while those on just $\mathrm{HF}$ and the chow diet showed similar amount of bile acids excretion as well as their CYP7A1 level, regardless of cholesterol intake (Fig. 4(C)).

Increase in mRNA expression of CYP7A1 (Fig. 5) was strongly correlated with faecal bile acid excretion (Table 5), and also to the weight of adipose tissue and plasma lipoproteins (Table 3). LXR $\alpha$, which serves as a dominant CYP7A1 activator in the liver, exhibited a significant increase upon CA consumption (Fig. 5) and was also significantly correlated with faecal bile acids excretion (Table 5). Our finding confirmed
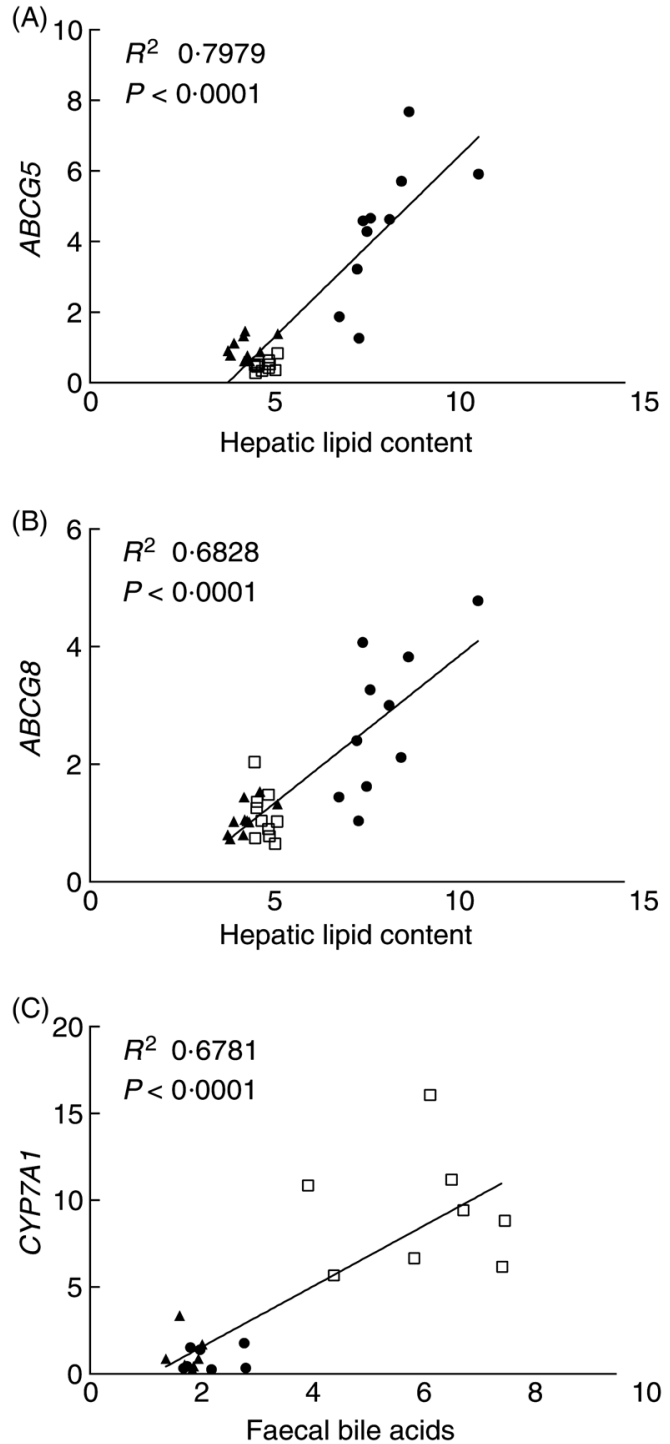

Fig. 7. Regression analysis of hepatic gene expressions and physiological changes. Linear regression analysis of (A) ATP-binding cassette subfamily $\mathrm{G}$ member 5 (ABCG5), (B) ATP-binding cassette subfamily $\mathrm{G}$ member 8 $(A B C G 8)$ and hepatic lipid content, and (C) cholesterol $7 \alpha$-hydroxylase (CYP7A1) and faecal bile acids. High-fat group, $\square$; high-fat + cholestyramine group; $\boldsymbol{\Delta}$, chow group.

the increase of $L X R \alpha$ previously reported in mouse and rat models ${ }^{(36,40)}$. These results supported that CA treatment regulates CYP7A1 through an LXR $\alpha$-dependent pathway. Coupled with the bile acid/CYP7A1 correlation discussed above, CA regulation of CYP7A1 may be through both pathways. Lower bile acid concentration de-repressed CYP7A1 transcription while an increase in $L X R \alpha$ also allowed for increased transcription.

The increased expression level of $A B C G 5 / 8$ was a major factor towards maintaining hepatic lipid and cholesterol levels (Fig. 5, Table 4). SREBP-1c, a transcription factor located upstream of fatty acid biosynthesis genes, expression was lowered by reduced circulating cholesterol (Fig. 5) and indicates that cholesterol level may mediate fatty acid metabolism. As shown in the IPA predicted upstream network in Fig. 6, $S R E B P-1 c$ can be suppressed by activation of LDL receptor, 
which matched our observation in the HF diet group in this study (Fig. 5). On the other hand, pathway analysis indicated that $S R E B P-1 c$ is regulated by multiple upstream transcriptional factors, including $L X R, R X R \alpha$ and STAT1 (Fig. 6). Similar changes in $A B C G 5 / 8$ and SREBP-1 $c$ had been observed in rats and mice treated with $\mathrm{CA}^{(31,41)}$, and in the intestine of hamsters fed chow supplemented with $4 \%(\mathrm{w} / \mathrm{w}) \mathrm{CA}$ and $0.15 \%(\mathrm{w} / \mathrm{w})$ lovastatin for 2 weeks ${ }^{(42)}$. A previous study in human subjects treated with $\mathrm{CA}(8 \mathrm{~g}$ twice per d) reported no change in $A B C G 5 / 8$ and SREBP-1c. Differences between this human study and animal studies might be due to the limited term (3 weeks) and small sample number of subjects $(n 5)^{(43)}$ and warrant further study.

In summary, our study using the hamster model provided additional molecular insights into the influence of circulating cholesterol on hepatic cholesterol metabolism pathways during hypercholesterolaemia produced by diets high in fat and cholesterol. CYP51 was identified as a marker of cholesterol homeostasis that may be regulated by multiple pathways. Reduced circulating cholesterol levels did not affect lipid metabolism genes (fatty acid synthase and acyl-CoA oxidase) or adipose weight. Additionally, CYP7A1 was identified to be regulated through an LXR-mediated pathway.

\section{Acknowledgements}

The authors would like to thank Dr Norberta Schoene for her comments on the manuscript.

This research was supported by USDA appropriate fund project no. 1235-51530-053-00D (T. T. Y. W).

H. H. designed and carried out the study, and wrote the manuscript; Z. X. carried out the study; W. Y. carried out the study and commented on the manuscript; L. Y. formulated the research question, designed the study and wrote the manuscript; T. T. Y. W. formulated the research question, designed the study and wrote the manuscript.

There were no conflicts of interest.

\section{References}

1. Ortega RM, Palencia A \& Lopez-Sobaler AM (2006) Improvement of cholesterol levels and reduction of cardiovascular risk via the consumption of phytosterols. Br J Nutr 96, S89-S93.

2. Goldstein JL \& Brown MS (1974) Binding and degradation of low density lipoproteins by cultured human fibroblasts: comparison of cells from a normal subject and from a patient with homozygous familial hypercholesterolemia. J Biol Chem 249, 5153-5162.

3. Kim H, Bartley GE, Rimando AM, et al. (2010) Hepatic gene expression related to lower plasma cholesterol in hamsters fed highfat diets supplemented with blueberry peels and peel extract. I Agric Food Chem 58, 3984-3991.

4. Bartley GE, Yokoyama W, Young SA, et al. (2010) Hypocholesterolemic effects of hydroxypropyl methylcellulose are mediated by altered gene expression in hepatic bile and cholesterol pathways of male hamsters. J Nutr 140, 1255-1260.

5. Zhao L, Chen Y, Tang R, et al. (2011) Inflammatory stress exacerbates hepatic cholesterol accumulation via increasing cholesterol uptake and de novo synthesis. J Gastroenterol Hepatol 26, 875-883.

6. Min HK, Kapoor A, Fuchs M, et al. (2012) Increased hepatic synthesis and dysregulation of cholesterol metabolism is associated with the severity of nonalcoholic fatty liver disease. Cell Metab 15, $665-674$.

7. van der Wulp MYM, Verkade HJ \& Groen AK (2013) Regulation of cholesterol homeostasis. Mol Cell Endocrinol 368, 1-16.

8. Jones PJH (1997) Regulation of cholesterol biosynthesis by diet in humans. Am J Clin Nutr 66, 438-446.

9. Lecerf JM \& de Lorgeril M (2011) Dietary cholesterol: from physiology to cardiovascular risk. Br J Nutr 106, 6-14.

10. Rudling M, Angelin B, Stahle L, et al. (2002) Regulation of hepatic low-density lipoprotein receptor, 3-hydroxy-3-methylglutaryl coenzyme A reductase, and cholesterol $7 \alpha$-hydroxylase mRNAs in human liver. J Clin Endocrinol Metab 87, 4307-4313.

11. Wolkoff AW \& Cohen DE (2003) Bile acid regulation of hepatic physiology. I. Hepatocyte transport of bile acids. Am J Physiol Gastroint Liver Physiol 284, G175-G179.

12. Repa JJ, Turley SD, Lobaccaro JMA, et al. (2000) Regulation of absorption and ABC1-mediated efflux of cholesterol by RXR heterodimers. Science 289, 1524-1529.

13. Suckling KE \& Jackson B (1993) Animal models of human lipid metabolism. Prog Lipid Res 32, 1-24.

14. Arbeeny CM, Meyers DS, Bergquist KE, et al. (1992) Inhibition of fatty acid synthesis decreases very low density lipoprotein secretion in the hamster. J Lipid Res 33, 843-851.

15. Kris-Etherton PM \& Dietschy J (1997) Design criteria for studies examining individual fatty acid effects on cardiovascular disease risk factors: human and animal studies. Am J Clin Nutr 65, S1590-S1596.

16. Chapman MJ (1986) Comparative-analysis of mammalian plasmalipoproteins. Methods Enzymol 128, 70-143.

17. Quig DW, Arbeeny CM \& Zilversmit DB (1991) Effects of hyperlipidemias in hamsters on lipid transfer protein activity and unidirectional cholesteryl ester transfer in plasma. Biochim Biophys Acta 1083, 257-264.

18. Oschry Y \& Eisenberg S (1982) Rat plasma lipoproteins: re-evaluation of a lipoprotein system in an animal devoid of cholesteryl ester transfer activity. J Lipid Res 23, 1099-1106.

19. Insull W Jr (2006) Clinical utility of bile acid sequestrants in the treatment of dyslipidemia: a scientific review. South Med J 99, 257-273.

20. Reagan-Shaw S, Nihal M \& Ahmad N (2008) Dose translation from animal to human studies revisited. FASEB J 22, 659-661.

21. German JB, Xu R, Walzem R, et al. (1996) Effect of dietary fats and barley fiber on total cholesterol and lipoprotein cholesterol distribution in plasma of hamsters. Nutr Res 16, 1239-1249.

22. Ametaj BN, Bobe G, Lu Y, et al. (2003) Effect of sample preparation, length of time, and sample size on quantification of total lipids from bovine liver. J Agric Food Chem 51, 2105-2110.

23. Folch J, Lees M \& Sloane Stanley GH (1957) A simple method for the isolation and purification of total lipides from animal tissues. J Biol Chem 226, 497-509.

24. Allen KGD, Bristow SJ \& Yu LL (2004) Hypolipidemic effects of modified psyllium preparations. J Agric Food Chem 52, 49985003.

25. Liu W, Wang HY, Yao WB, et al. (2010) Effects of sulfation on the physicochemical and functional properties of a water-insoluble polysaccharide preparation from Ganoderma lucidum. I Agric Food Chem 58, 3336-3341.

26. Yuan JS, Reed A, Chen F, et al. (2006) Statistical analysis of realtime PCR data. BMC Bioinformatics 7, 85.

27. Jakobsson T, Treuter E, Gustafsson JA, et al. (2012) Liver X receptor biology and pharmacology: new pathways, challenges and opportunities. Trends Pharmacol Sci 33, 394-404.

28. Yoon M (2009) The role of PPAR $\alpha$ in lipid metabolism and obesity: focusing on the effects of estrogen on PPAR $\alpha$ actions. Pharmacol Res 60, 151-159.

29. Boone LR, Brooks PA, Niesen MI, et al. (2011) Mechanism of resistance to dietary cholesterol. J Lipids 2011, 101242.

30. Harada LM, Carrilho AJF, Oliveira HCF, et al. (2006) Regulation of hepatic cholesterol metabolism in CETP+/-/LDLR+/- mice by 
cholesterol feeding and by drugs (cholestyramine and lovastatin) that lower plasma cholesterol. Clin Exp Pharmacol Physiol 33, 1209-1215.

31. Shibata S, Hayakawa K, Egashira Y, et al. (2007) Roles of nuclear receptors in the up-regulation of hepatic cholesterol $7 \alpha$-hydroxylase by cholestyramine in rats. Life Sci $\mathbf{8 0}, 546-553$.

32. Halder SK, Fink M, Waterman MR, et al. (2002) A cAMPresponsive element binding site is essential for sterol regulation of the human lanosterol 14 $\alpha$-demethylase gene (CYP51). Molec Endocrinol 16, 1853-1863.

33. Fink M, Acimovic J, Rezen T, et al. (2005) Cholesterogenic lanosterol $14 \alpha$-demethylase (CYP51) is an immediate early response gene. Endocrinology 146, 5321-5331.

34. Chen WL, Owsley E, Yang YZ, et al. (2001) Nuclear receptormediated repression of human cholesterol $7 \alpha$-hydroxylase gene transcription by bile acids. J Lipid Res 42, 1402-1412.

35. Acimovic J, Fink M, Pompon D, et al. (2008) CREM modulates the circadian expression of CYP51, HMGCR and cholesterogenesis in the liver. Biochem Biophys Res Commun 376, 206-210.

36. Matsumoto K \& Yokoyama S (2010) Gene expression analysis on the liver of cholestyramine-treated type 2 diabetic model mice. Biomed Pharmacother 64, 373-378.

37. Daggy BP, Oconnell NC, Jerdack GR, et al. (1997) Additive hypocholesterolemic effect of psyllium and cholestyramine in the hamster: influence on fecal sterol and bile acid profiles. J Lipid Res 38, 491-502.

38. US Census Bureau (2012) Health and nutrition. In Compendia, p. 140. Statistical Abstract of the United States. http://www2.census.gov/library/publications/2011/compendia/statab/131ed/2012statab.pdf (accessed February 2016).

39. Suckling KE, Benson GM, Bond B, et al. (1991) Cholesterol lowering and bile-acid excretion in the hamster with cholestyramine treatment. Atherosclerosis 89, 183-190.

40. Gupta S, Pandak WM \& Hylemon PB (2002) LXR $\alpha$ is the dominant regulator of CYP7A1 transcription. Biochem Biophys Res Commun 293, 338-343.

41. Kamisako T, Ogawa H \& Yamamoto K (2007) Effect of cholesterol, cholic acid and cholestyramine administration on the intestinal mRNA expressions related to cholesterol and bile acid metabolism in the rat. J Gastroenterol Hepatol 22, 1832-1837.

42. Field FJ, Born E \& Mathur SN (2004) Stanol esters decrease plasma cholesterol independently of intestinal $\mathrm{ABC}$ sterol transporters and Niemann-Pick C1-like 1 protein gene expression. J Lipid Res 45, 2252-2259.

43. Nilsson LM, Abrahamsson A, Sahlin S, et al. (2007) Bile acids and lipoprotein metabolism: effects of cholestyramine and chenodeoxycholic acid on human hepatic mRNA expression. Biochem Biophys Res Commun 357, 707-711. 